\title{
Rooming-in organization to prevent neonatal mortality and morbidity in late preterm infants
}

\author{
Mariano Manzionna ${ }^{1 *}$, Antonio Di Mauro $^{2}$ \\ From XX National Congress of the Italian Society of Neonatology \\ Rome, Italy. 9-11 October 2014
}

Despite most infants born at $34+0$ through $36+7$ weeks' gestation are thought to be at low risk during the birth hospitalization and have a neonatal course with no significant complications, they are physiologically and metabolically immature with an higher rates of morbidity and mortality than term infants [1].

Most common medical condition associated with latepreterm births are respiratory distress, apnea, temperature instability, hypoglycemia, hypocalcemia, jaundice, poor feeding, sepsis and finally an higher rates of the hospital readmissions during the neonatal period. These morbidities result in workup for sepsis evaluations, antibiotic therapy, intravenous fluid administration, ventilatory support and increased length of stay with higher hospital costs [2].

Rooming-in organization of late preterms births aims to assess and identify risk factors, prevent and manage potential medical complications during hospitalization. Interventions and practices reccomended are illustred in table 1.
Evidence of physiologic maturity, feeding competency, thermoregulation and absence of medical of medical illness are minimum discharge criteria for late-preterm newborns. Furthermore it's of great importance to assess educational programs with special instruction and guidance to parents, engaging families in providing appropriate home care after hospital discharge. A long term follow-up arrangements is also recommended to assess and plan early interventions in case of neurodevelopment delay [4].

We conclude that, based on the significant morbidity and mortality of late preterm births, the health care focus on prematurity should be expanded to include the late preterm period.

\section{Authors' details}

'Pediatric Unit, Maternal and Child Health Department, S. Giacomo Hospital, ASL BA, Monopoli (Bari), Italy. ${ }^{2}$ Neonatology and Neonatal Intensive Care Unit, Department of Biomedical Science and Human Oncology, University of Bari "Aldo Moro", Bari, Italy.

\section{Table 1 Assessment and care of the late preterm infant [3].}

\footnotetext{
Assess gestational age of neonate

Assess and monitor respiratory status

Appropriate respiratory interventions

Assess for risk factors and symptoms of heat loss and/or cold stress

Interventions to maintain a neutral thermal environment

Assess for maternal and neonatal risk factors for sepsis

Antibiotic therapy and diagnostic evaluation if sepsis is suspected

Assess for presence of jaundice and hyperbilirubinemia

Phototherapy as indicated

Parent education regarding signs and symptoms of jaundice and hyperbilirubinemia

* Correspondence: mariano.manzionna@alice.it

'Pediatric Unit, Maternal and Child Health Department, S. Giacomo Hospital,

ASL BA, Monopoli (Bari), Italy

Full list of author information is available at the end of the article
}

Interventions and assessment of hypoglycemia including transfer to higher acuity unit or facility if indicated

Breastfeeding, and support for breastfeeding mothers including observation, education and validation

Discharge planning including parent education, counseling, and validation of knowledge about recognizing and acting on risk factors 


\section{References}

1. Engle WA, Tomashek KM, Wallman C: "Late-Preterm" Infants: A Population at Risk. Pediatrics 2007, 120(6):1390-1401.

2. Engle WA: Infants Born Late Preterm: Definition, Physiologic and Metabolic Immaturity, and Outcomes. Neoreviews 2009, 10(6):280-286.

3. Association of Women's Health, Obstetric, and Neonatal Nurses (AWHONN): Assessment and Care of the Late Preterm Infant Evidence-Based Clinical Practice Guidelines. Washington, DC: AWHONN; 2010.

4. Kugelman A, Colin AA: Late preterm infants: Near Term But Still in a Critical Developmental Time Period. Pediatrics 2013, 132(4):741-751.

doi:10.1186/1824-7288-40-S2-A4

Cite this article as: Manzionna and Di Mauro: Rooming-in organization to prevent neonatal mortality and morbidity in late preterm infants.

Italian Journal of Pediatrics 2014 40(Suppl 2):A4.

\section{Submit your next manuscript to BioMed Central} and take full advantage of:

- Convenient online submission

- Thorough peer review

- No space constraints or color figure charges

- Immediate publication on acceptance

- Inclusion in PubMed, CAS, Scopus and Google Scholar

- Research which is freely available for redistribution

Submit your manuscript at www.biomedcentral.com/submit 